\title{
Chapter 9 \\ THE ENGINEERING APPLICATION OF SEA AND SWELL DATA
}

Richard H. Fleming and Charles C. Bates

Hydrographic Office, Department of the Navy

Washington, D. C.

\section{INTRODUCTION}

In planning for any marine construction, information on ocean waves should be considered essential. Such information must be avallable to select the best season of operations and to indicate the types of floating equipment that can be operated economically with a minimum of lost time. Furthermore, from such advance information $1 t$ will be possible to estimate whether or not special observing and forecasting services will be required to provide for safe and efficient day-to-day operations.

Readily avallable sources of ocean wave information are the sea and swell atlases published by the U.S. Navy Hydrographic offlce. These atlases, providing world-wide coverage on a monthly basis, have been complled from visual observations of sea and swell recorded aboard merchant and naval vessels. These data therefore provide a means for making rapid evaluations of wave and swell conditions in the area of operations and along routes to and from this area. If the site is on an exposed coast, it is also possible to estimate surf conditions.

Although the data are not ideal for many specific purposes, they are very helpful when used to derive index values of wave conditions. Such values will indicate changes from month to month and from one locallty to another. An engineer with experience in one region can, therefore, by use of such index values tell whether conditions in another area will be worse or better. If other environmental features such as winds, currents, temperatures, etc, are also taken into account, it is possible to designate analogous areas so that experience in known regions can be extrapolated into unfamiliar regions.

\section{WORK FEASIBILITY}

In order to interpret wave data, it is essential to have an understanding of work feasibility. This is a measure of efflclency and safety of one or more types of operations expressed in terms of one or more environmental factors. For example, small craft may operate unhampered while waves are small, but if the wave helghts exceed some limit, the efficlency and safety decrease as the waves grow larger, until with waves above a certain size operations must be stopped entirely. Other more complicated situations can be imagined where more than one variable must be taken into account. Thus, the efficiency of dredging operations may depend upon waves and currents, while the efficiency of plle-driving may depend on rainfall as well as wave height. The importance of the concept of work feasibility is very obvious if the operation must be conducted in a region of extreme and severe conditions where effectiveness will be marginal, or must be limited to brief periods of time.

Unfortunately our knowledge of work feasibility is extremely limited. There exists a reasonable amount of information about many of the environmental factors, but the applications of such data to engineering operations will be qualitative until such a time as more is known about the relationships between these factors and varlous types of operations. Fortunately a firm of consulting oceanographers working with the oil companies on the Gulf coast has, during the last several years, been able to make a start on this problem. Table I, based on these studies, shows the limits of performance in terms of wave heights for a number of different operations (Glenn, 1950). Such relationships can be employed in several different ways. If, for example, the percentage frequency of occurrence of waves of different heights is known for any region, it is possible for the planner to estimate the amount of time that any operation can be conducted efflciently, with marginal 
THE ENGINEERING APPLICATION OF SEA AND SWELL DATA

TABLE I

GENERALIZED PERFORMANCE DATA FOR MARINE OPERATIONS

(According to Glenn)

\begin{tabular}{|c|c|c|c|}
\hline \multirow[b]{2}{*}{ Type of Operation } & \multicolumn{3}{|c|}{ Wave Heights* (in feet) for: } \\
\hline & $\begin{array}{l}\text { Safe, Efficient } \\
\text { Operation }\end{array}$ & $\begin{array}{l}\text { Marginal } \\
\text { Operation }\end{array}$ & $\begin{array}{l}\text { Dangerous and/or } \\
\text { Inefficient } \\
\text { operation }\end{array}$ \\
\hline $\begin{array}{l}\text { Deep Sea Thu } \\
\text { Handling oll and water barge } \\
\text { Towing oil and water barge } \\
\text { Handling derrick barge } \\
\text { Handling and towing LST-type vessel }\end{array}$ & $\begin{array}{l}0-2 \\
0-4 \\
0-2 \\
0-3\end{array}$ & $\begin{array}{l}2-4 \\
4-6 \\
2-3 \\
3-5\end{array}$ & $\begin{array}{l}>4 \\
>6 \\
>3 \\
>5\end{array}$ \\
\hline $\begin{array}{l}\text { Crew Boats, } 60-90 \text { feet in length } \\
\text { Underway } \\
\text { Loading or unloading crews at } \\
\text { platform }\end{array}$ & $0-3$ & $8-15$ & $\begin{array}{l}>15 \\
>5\end{array}$ \\
\hline $\begin{array}{l}\text { Supervisor's Boats, fast craft } \\
\text { 30-50 feet in length } \\
\text { Underway at crulsing speed } \\
\text { Loading or unloading personnel } \\
\text { at platform or floating } \\
\text { equipment }\end{array}$ & $\begin{array}{l}0-2 \\
0-2\end{array}$ & $\begin{array}{l}2-4 \\
2-4\end{array}$ & $\begin{array}{l}>4 \\
>4\end{array}$ \\
\hline $\begin{array}{l}\text { LCT-type Vessel and Cargo Luggers } \\
\text { Underway } \\
\text { Loading or unloading at platform } \\
\text { Loading or unloading at floating } \\
\text { equipment }\end{array}$ & $\begin{array}{l}0-4 \\
0-3 \\
0-4\end{array}$ & $\begin{array}{l}4-5 \\
3-4 \\
4-5\end{array}$ & $\begin{array}{l}>5 \\
>4 \\
>5\end{array}$ \\
\hline Buoy Laying (using small Derrick Barge) & $0-2$ & $2-3$ & $>3$ \\
\hline $\begin{array}{l}\text { Platform Bullding } \\
\text { Using ship-mounted derrick } \\
\text { Using large derrick barge }\end{array}$ & $\begin{array}{l}0-4 \\
0-3\end{array}$ & $\begin{array}{l}4-6 \\
3-5\end{array}$ & $\begin{array}{l}>6 \\
>5\end{array}$ \\
\hline Pipe-line construction & $0-3$ & $3-4$ & $>4$ \\
\hline $\begin{array}{l}\text { Gravity-meter exploration using sur- } \\
\text { face vessel (limiting conditions } \\
\text { caused by instrument becoming } \\
\text { noisy) }\end{array}$ & $0-4$ & $4-6$ & $>6$ \\
\hline $\begin{array}{l}\text { Selsmograph Exploration using craft } \\
\text { under } 100 \text { feet in length }\end{array}$ & $0-6$ & $6-8$ & $>8$ \\
\hline $\begin{array}{l}\text { Large Amphiblous Alrcraft (PBY) } \\
\text { Sea Landings and Take-off's } \\
\text { Boat-to-plane transfer operations } \\
\text { in water }\end{array}$ & $0-1.5$ & $1.5-3$ & $>3$ \\
\hline Small Amphiblous Alrcraft & $0-1$ & $1-2$ & $>2$ \\
\hline
\end{tabular}

*Wave heights used are those of the average maximum waves. Height limits given above are not rigid and will vary to some extent with locality, local wind conditions, experience of personnel, etc. 
efficlency, or with dangerous working conditions. Furthermore, during a marine operation, day-to-day scheduling can be based upon wave forecasts expressed in operational terms. Disaster and evacuation plans also can be formulated so that they can be carried out with safety and speed before the situation becomes critical. It should be pointed out that the information in Table I is based on observations and experlence gained on the Loulsiana coast. It is believed that the relationships are generally usable in other areas but further checking is desirable.

\section{EXISTING TYPES OF PUBLISHED SEA, SWELL, AND WIND DATA}

Unfortunately, a direct correlation between work feasibility and wave height based on published sea and swell data is not possible. Sea and swell observations are usually described in codes based on a 10-point scale describing the sea surface in general terms, such as "smooth", "rough", "mountainous", etc., without speciflc reference to wave helghts. Swell is reported in such terms as "short and high". However, these general terms have the approximate numerical wave helght equivalents shown in Table II which 1llustrates the sea and swell codes currently in use by cooperating marlne observers of the U.S. Navy Hydrographic Off1ce. The coarseness of these observations has cast some doubts on their reliab1lity. When used with judgment, however, the data are of considerable value, particularly since no other data of this sort exist for the oceans of the world except that provided by the "hindcast" method. British and Japanese sea and swell atlases have been complied from essentially similar data based upon visual observations. These data cover several decades, the files at the U.S. Navy Hydrographic Office dating back to 1904 . The data are published by these governments in the varying formats shown in F1gs. 1 and 2. Of the several methods of presentation, the "rose" employed in the American presentation (Hydrographic office, 1943 to 1950), is the most sultable for the technical user. However, it should be mentioned that the American rose is oversimplified and that data are omitted if the condition occurs less than $7 \%$ of the time; moreover, the data are obscured if the frequency of occurrence is between $7 \%$ and $14 \%$ of occasions. The detalled tabulations are on file, however, at the U.S. Navy Hydrographic office and can be made avallable upon request for the cost of reproduction of the tabulation sheets.

In addition to tabulations of sea and swell conditions, the frequency of occurrence of various wind forces may also be of great use in providing enough data to provide a reliable sample, climatically speaking. Such a sample should extend over at least a 10-year period and contain more than 100 observations per month. Mariners and marine meteorologists for years have used the rule of thumb that on the high seas the wind force is one number higher than the sea state. This correlation strongly biases the wind and sea data in existence today, as found by A. E. Parr and W. T. Edmondson in an unpublished analysis carried out in 1943. The approximate correlation permits wind strength, when reported, to be converted into height of local wind waves for exposed water areas, thereby increasing the number of observations avallable. Sultable corrections may be made for fetch Iimitations if the wind blows over a water area of 150 miles or less. CIlmatic wind data exist for many coastal points throughout the world and also are presented in very sultable "rose" form in the British A1r Ministry series of Monthly Meteorological Charts for various oceans.

\section{CONVERSION OF PUBLISHED SEA, SWELL, AND WIND DATA INTO FREQUENCY OF WAVE HETGHT}

With the necessary climatic data at hand on sea state, swell condition, and wind force for a given area, it is possible to convert these values into terms of specific waye height and thus into terms of work feasibility for the type of marine construction to be conducted. The equation for determining the frequency of occurrence of the specifled wave helght is as follows:

$$
P=1 / 2(W+X)-k(100-Y)
$$

where,

$$
\begin{aligned}
& P=\text { Probable frequency of suitable wave height } \\
& W=\text { Probable frequency of suitable wind force }
\end{aligned}
$$




\section{TABLE II}

\section{SCALES USED IN SEA AND SWELL ATLASES OF THE U. S. NAVY HYDROGRAPHIC OF FICE}

ATLAS

TERMINOLOGY

BEA CONDMIONG, U. B. HXDROGRAPEIC OFHICE GCAWE Apprex. Code

CALM O

LOW $\left\{\begin{array}{l}\text { Leas than } \\ 1 \text { loot } \\ 1-3 \text { toot }\end{array}\right.$

MEDIUM $\left\{\begin{array}{l}3-6 \text { bot } \\ 5-8 \text { toet }\end{array}\right.$

$\int_{2-20 \text { set }}^{8-121000 t}$

20-40 seet

40 feet

and over

0

2

3
4

VerF RodGH-The medium waves become larger and begin to
heap up, the whitecapping is continuous, and the seas break cccssionally; the form from the capping and breaking waves begins to be blown along in the direction of the wind. The breaking and capping seas produce a perpetual murmur.

Hron-Heavy, whitecapped waves that show a risible tncrease in height and are breaking extensively. The foam is blown in dense streaks along in the direction of the wind. The ses begins to roll and the noise of the breaking seas is like a dull roar, sudible at greater distance.

VERY HIan-High, heavy waves developed with long overhanging crests that are breaking continuously, with a parpetual roaring noise The whole surfoce of the sen takes on a polt Whito sppearance from tho great amount of the ses taks on along with the wind. The rolling of the sea becomes hesvy and shocklike.

Mountanious-The heavy waves become so high that ships within close distances drop so low in the wave troughs that for $a$ time they are lost from view. The rolling of the sea becomes tumultuous. The wind beats the breaking edge of the seas into 8 troth, and the whole sea is covered with dense streales of foam being carried along with the wind. Owing to the violence of the wind the sir is so flled with loam and spray that relatively close objects are no longer visible.

9 tions, e. g., $(6-9)$. A very rough, confused sea.

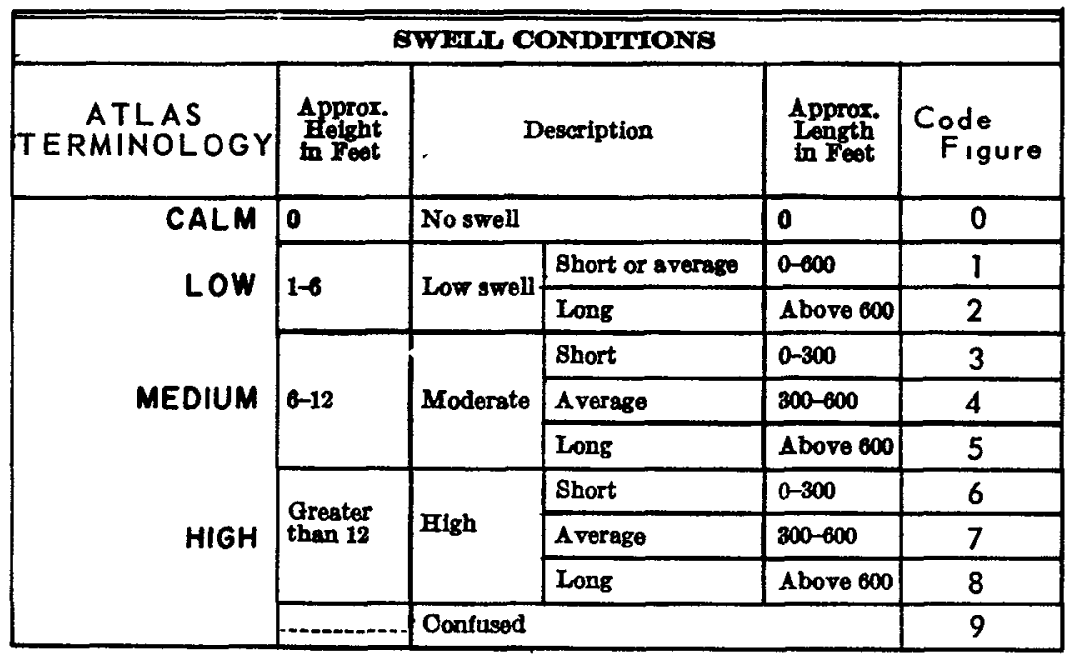


UNITED STATES<smiles>CC(C)(C)C(C)(C)C(C)(C)C</smiles>

rereerrage scane

METHOD OF PRESBNTATION

The rose shows both graphically and by
figures the character of the $8 w e l l$ for figures the character of the swell tor a sthe percent of direction is less than 7 . When the percent of direction 18 greater than 14, conditions are shown along the shaft in percentage of low and medium swell, when the unshown ramainder be ing percent of direction is between 6 and 15 , the condtilons within the direction are shown by the letters $\mathrm{L}, \mathrm{M}$, or $\mathrm{H}$, meaning

predominantly "low", "medium", or "hile

The lower left-hand figure is the number of observations, and the lower
ficure the number of calms.
GREAT BRITAIN

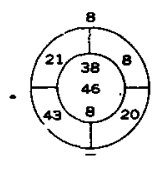

117

METHOD OF PRESE NTATION

The figures in the outer ring show the percent28e frequency of Bwell from each quadrant from top to bottom the frequencies of 81 ltht, moderate, and heavy swell from all directions. The igure above the cuter circie gives the percentage frequency of no swell thathe percentage frequency of "confused swell".
The tigure in the lower loft-hand corner is the mumber of observations.
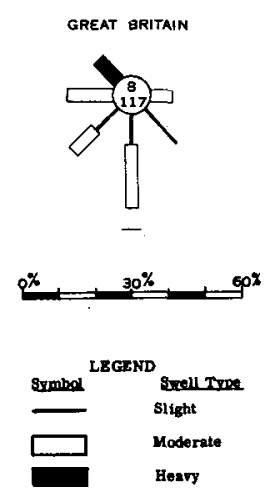

The upper tigure in the center of the rose shows the percentzge frequency the number of observations. The tirgure below the rose glves the per.
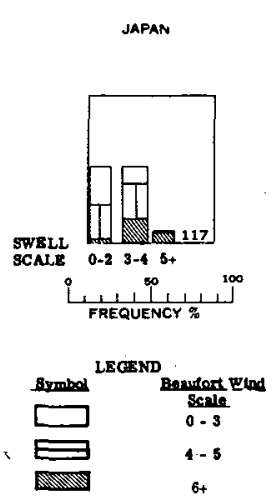

The figure in the lower right-hund cornor is the mimber $\alpha$ obeerration

FIg. 1

Methods utilized by meteorological and.hydrographic activities of Great Britain, Japan, and the United States for presenting climatic data on swell conditions.

UNITED STATES<smiles>CC(C)(C)C(C)(C)C(C)(C)C</smiles>

PERCENTAge SCALE

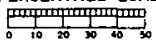

METHOD OF PRESENTATION

The rose shows both graphically and by figures the character of the seas for a specified ared.

No arrow is shown when the percent of direction

is less than 7 . When the percent of direction is

greater than 14 , conditions are shown along the

shaft in percentage of low and medium seas,

with the unshown remainder being the percent of

high seas. When the percent of direction is

between 6 and 15 , the conditions within the direc-

tion are shown by the letters $L, M$, or $H$, meaning

predominantly "low", "medium", or"higH".

The upper left-hand figure is the number of observations and the upper right-hand figure the percent of calms.
JAPAN

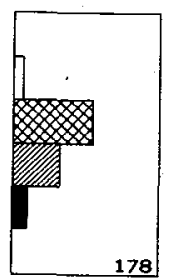

PERCENTAGE SCALE
TITITTTT

LEGEND

\section{Symbod Class of Waye}

Calm (0-2)

Low (3-4)

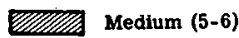

High (7-9)

Figure in lower right-hand corner is number of observations

Fig. 2

Methods utilized by hydrographic activities of Japan and the United States for presenting climatic data on sea conditions. 


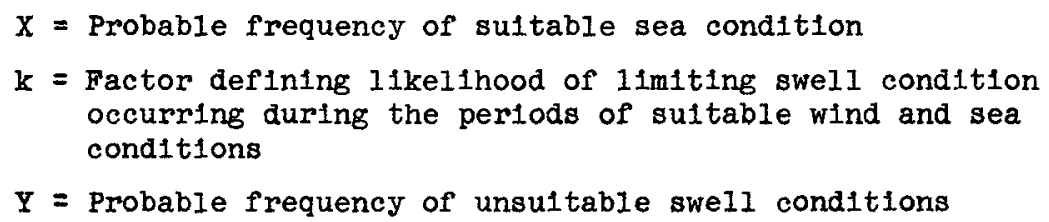

If there are 200 or more "state of sea" observations for a given month, wind observations do not need to be included in the computation. If the number is less, however, wind observations should be incorporated so as to give a better climatic average. The value of " $k$ " is difficult to assess, for in some parts of the world, the sea may be calm, and yet swell occurs which is high enough to inhibit operat1ons. In other words, the value of " $k$ " may vary from zero to 100 percent. In practlce, a very low value of " $k$ " is used and upon occasion, a value of zero is indicated.

As an example of the method, assume that a determination was desired of the frequency with which waves 3 feet or more in helght occurred at a given point totally exposed to oceanic conditions. The monthly occurrence of the defining factors is reported to be as follows:

\section{Wind of force 4 or less: $85 \%$ frequency \\ Calms and low seas: $75 \%$ frequency \\ Moderate and high swell, plus half of the occurrence of low swell: $30 \%$ frequency}

Under such clrcumstances, wind and wind wave conditions would be considered favorable $80 \%$ of the time. If the value of " $k$ " were 0.2 , then swell over 3 feet in helght would occur when seas were below that helght or about $6 \%$ of the time $(0.2 \times 30 \%)$. When these values are substituted in the equation just given, the equation becomes:

$$
P=0.5(85+75)-0.2(30)=74
$$

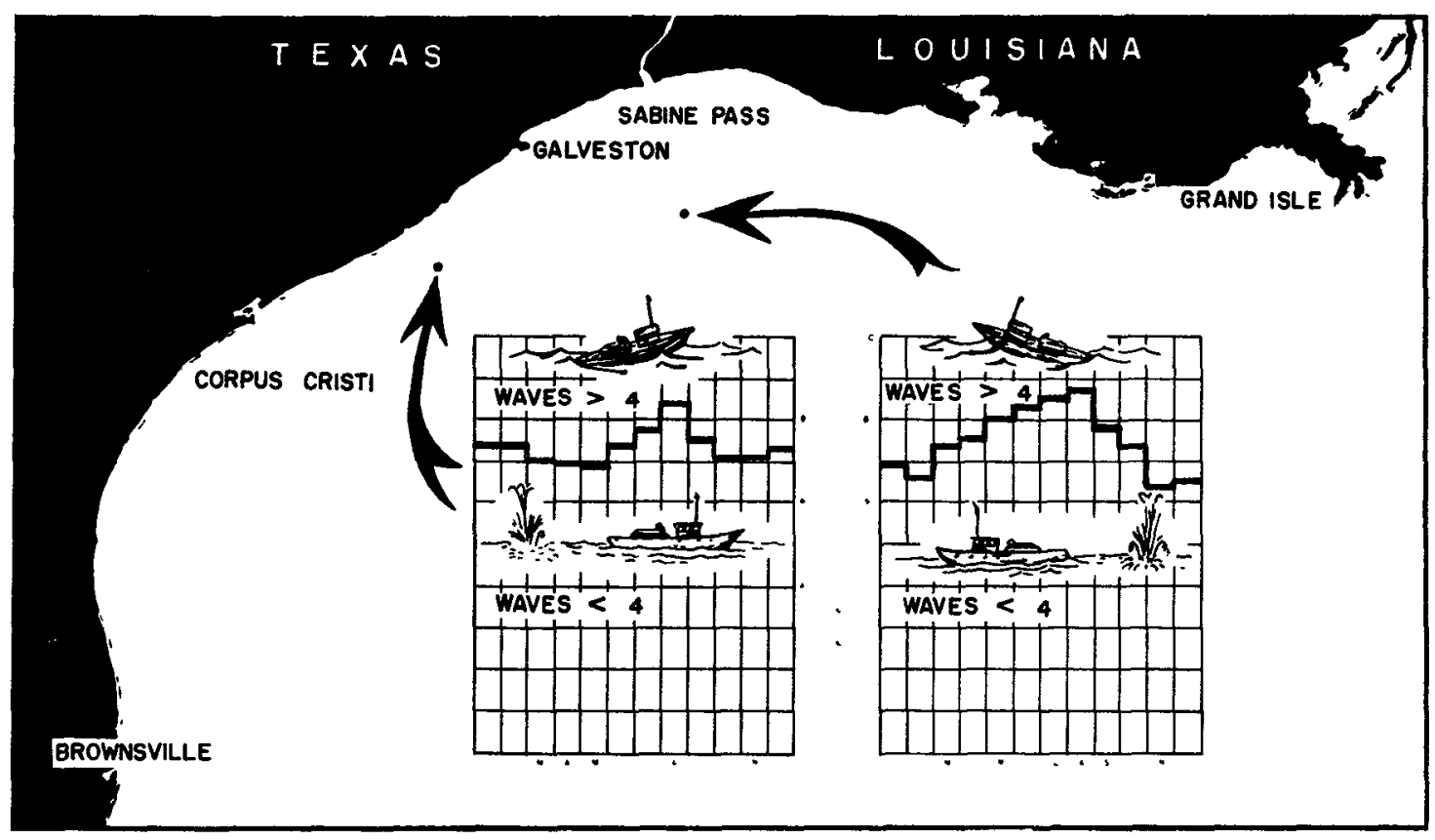

Fig. 3

Probable frequency of occurrence of wayes above and below 4 feet in helght at two selected locations in the Gulf of Mexico. 


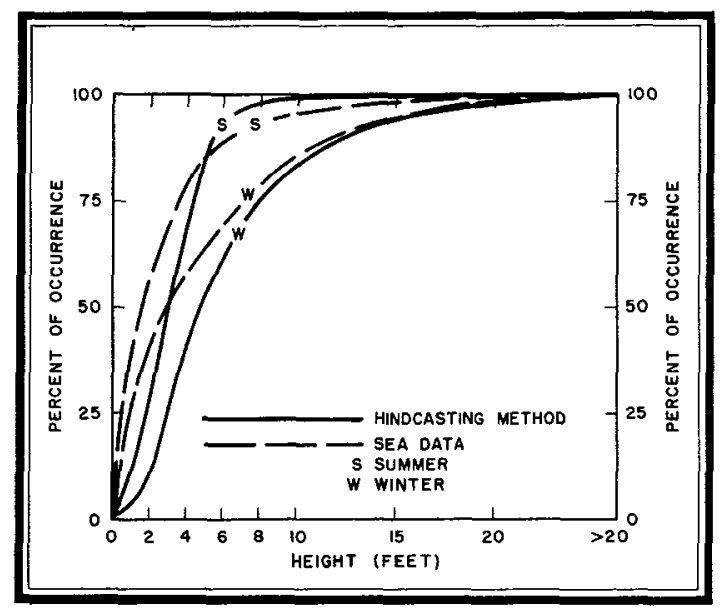

Fig. 4

Comparison of wave height data obtained by the hindcasting and climatic techniques for the 10cation, Latitude $28^{\circ}$ North, Longitude $177^{\circ} 30^{\prime}$ East, near Midway Island.

some question. Fortunately, oceanographers at the Scripps Institution of Oceanography have made "hindcasts" of average wave heights in the open sea by the method outlined by R. S. Arthur in Chapter 8. A comparison of the two methods for a location in the Pacific near Midway Island is shown in F1g. 4. The number of observations and hindcasts used is approximately the same in each case -- 90 per month. The best correlation is obtained when no correction is made for the occurrence of swell independently of sea, $1 . e$. , the " $k$ " factor is zero. The greatest discrepancy is noted between wave heights of 4 to 12 feet, the zone in which the mariner is commonly belleved to overestimate wave heights. A comparison of various aspects of the two methods for obtaining probable wave conditions is given in Table III.

\section{TABLE III}

\section{COMPARISON OF CLIMATIC AND HINDCASTING METHODS FOR PROVIDING WAVE INFORMATION} Aspect

Accuracy

cost

\section{Comparison}

Hindcasting provides more specific information on wave height, period, and direction than does the climatic method when:

a. There is adequate weather map coverage, preferably at 12-hourly intervals or less.

b. Locations are outside the equatorial region bordered by latitudes $20^{\circ}$ north and south. Inside this region, the hindcasting method falis and the climatic method is the only one available unless wind observations are used from shore sites.

c. There is no swell from the Southern Hemisphere. (Both methods fall to provide adequate information on this condition).

d. There are several swell trains or the height of swell is low compared to that of the local wind waves. (climatic observations from beach sites detect such low swell, but marine observers do not.)

Climatic method is 25 or more times faster than the hindcasting method. Majority of tabulation in the climatic method can be conducted by sub-professional personnel, but most of work in hindcasting method is at the professional level. 


\section{ROUTE SELECTION}

In addition to using tabulated wave data for computing conditions at an exposed oceanic site, the data may be applied to evaluating the suitability of routes to the site, since problems arise in the dispatching of small craft and towed barges to points hundreds of miles away through exposed waters. Such an evaluation is based on computing the frequency of occurrence of suitable conditions along the several routes under consideration. Since each route goes through several areas for which sea and swell conditions are given, it is necessary to arrive at a resultant value of the frequency of occurrence of acceptable wave heights in the areas making up a route. The resultant value can be obtained by correlating the frequencies of occurrence for each component area with each other. The minimum time during which suitable conditions exist simultaneously in each of these areas would be that of the areas being completely independent of each other, or the product of the percentage frequencles for each area. The maximum time during which suitable conditions would exist simultaneously is the value of the lowest component frequency of the assoclated areas. The exact degree of correlation falls somewhere between these maximum and minimum values. The mean of these extremes is probably a satisfactory value for the purpose of comparing one route against another.

As an example of such a route selection, a problem is shown here which was worked out for crossing the Bay of Bengal from India to Malaya during the summer monsoon. The pertinent frequencies of occurrence of suitable conditions for a given type of operation are shown in Fig. 5. The direct route is noted to pass through four quadrangles with desired conditions existing $82 \%, 58 \%$, 68\%, and $82 \%$ of the time respectively. Such values give the best possible frequency of occurrence of sultable passage as $58 \%$, the worst $24 \%$, and the probable value of occurrence about $41 \%$ of the time. Values computed for routes to the north and south of the direct route indicate that the southern route is the best of the three and is likely to have suitable conditions about a third of the time more frequently than does the direct route.

\section{COMPUTATION OF SURF CONDITIONS}

The coastal engineer is as interested, if not more so, in wave conditions in shallow water, including the surf zone, as he is in conditions outside this zone. climatic wave data can also be used in this problem. However, the determination of probable surf helghts is not as easy or as accurate as the one just described for determining wave conditons offshore, because the transformation of deep water waves into surf is difficult to determine for a short strip of beach even when full information is at hand on the deep water characteristics of the wave trains, on the beach topography, on the off shore hydrography, and on local tidal currents. A method worked out by the junior author, however, and described elsewhere (Bates, 1948) does permit the climatic data to be converted into frequency of surf heights along a given orientation of beach for the area for which the wave data are avail- 
able, it belng assumed that such a coast has smooth and parallel depth contours offshore. The method takes into account the three major factors required in surf forecasting, namely, deep water wave height, approximate wave period, and the angle which the deep-water wave crests forms with the coastine. By following eight successive steps too lengthy to be discussed here, the probable monthly frequency of a given surf height then can be determined.

\section{UNPUBLISHED TYPES OF VISUALLY OBSERVED WAVE DATA}

In addition to the published sea and swell atlases summarizing conditions at sea, there exists a large amount of observations of sea conditions for coastal points throughout the world. Although in manuscript form, these data are generally on file at the U.S. Navy Hydrographic office. Weather observers have noted the sea state for periods ranging from $I$ to 9 years at 157 coastal localities on the European coast, and at 3 localities in Asia Minor. Observations have been made from 9 German lightships in the North and Baltic Seas between 1936 and 1937 , and by French shore observers at several points on the western coast of French Morocco since 1931. In addition, observations were made visually two or three times a day for 57 points in southern and eastern England and on the French invasion coast between March and November, 1944. Similar observations made during several months in 1945 are ava11able for 8 points along the Bay of Bengal. On the North Amerlcan coast, the U.S. Coast Guard has made measurements using wave staffs between 1944 and 1947 at 12 coastal points in the United States and Alaska, as well as one location each in Puerto Rico and Hawaii. Fifteen thousand wave observations have been collected since 1947 by Glenn and Assoclates from numerous driling platforms off the Louisiana coast. In the far Pacific observations were made on okinawa and Iwo Jima for several months during the invasions of those islands in 1945.

\section{INSTRUMENTALLY OBSERVED WAVE DATA}

Instrumental observations of waves are much rarer. With the exception of certain Russian wave-measuring equipment operated on the Black Sea coast, the oldest set of instrumentally recorded wave data is that obtained with the drum recorder at the Scripps Institution of oceanography, which began operation in the late 1930's (Shepard and LaFond, 1940). The more recent Atlantic and Pacific coast installations of wave recorders have been described by F. F. Snodgrass in Chapter 7 . In the Gulf of Mexico, the Beach Erosion Board wave recorder installed on a well platform of the Humble 011 \& Refining Company five miles off Grand Isle, Louisiana, is the sole source of instrumentally observed wave data for that body of water. The Woods Hole Oceanographic Institution has collected some data from Bermuda and at Cuttyhunk, Massachusetts. In England, the British Admiralty has maintained a wave recorder on the Atlantic coast of Cornwall from 1944 to the present time. The former Deutsche Seewarte of Hamburg, Germany, operated one or more recorders upon occasion in the North Sea.

\section{VALUE AND COST OF WAVE DATA}

As can be seen from this resumé, the locations for which instmumentally recorded data are avallable throughout the world are st1ll relatively sparse, and the data are, with only a few exceptions, available only in manuscript reports. In view of this situation, the climatic data, even though based on visual observations, appear to be the best currently available on a worldwide basis. The limitations of these data have already been outlined in Table III, but many of these restrictions can be overcome if the data are treated as indexes instead of rigid numerical values for the occurrence of a certain wave height. Using the index concept, the data lend themselves readily to rapid comparisons of changes of wave conditions from one month to the next for a given location or to the comparison during a given month of one locality with another. If these qualitative data are further keyed into the experience of an individual for a given locality or into the instrumentally recorded conditions for a wave recorder, a more reliable extrapolation is possible for areas in which neither experience nor instrumentally recorded data are avallable.

The costs of marine work are unusually high. With even small dredges charterIng for $\$ 900$ or more per day, pile drivers renting at $\$ 300$ and up per day, and 
small channels silting up within 30 days of dredging because of wave action, as one concern found after spending $\$ 60,000$ on the job, it is easy to understand why the oil industry has spent 234 million dollars to drill 190 wells in the Gulf of Mexico since 1938. Costs in harbor construction are certainly of the same order of magnitude, although a larger pereentage of the funds may come from public, rather than private sources. With costs such as these, increases in efficiency from adequate planning against wave action provide an enticing way to save money. The cost of a preliminary survey of wave conditions based on tabulated sea and swell data is less than $\$ 100$ per location, and often considerably less than half that amount. If the preliminary study indicates that wave conditions are important factors in design and operation, a more detailed study is called for based on an elaborate analysis of wave conditions, using hindcasting and the preparation of wave refraction diagrams. The cost of such a study will probably range between $\$ 2,000$ and $\$ 4,000$. The initial study also may have indicated that the work must be conducted during periods when wave heights may approach or exceed safe working Iimits upon occasion, making proper scheduling of work and storm evacuation plans a necessity. In such a case, accurate wave and weather forecasts should be acquired through special arrangement with the government weather service if the construction job is being conducted by a government agency and through arrangement with a private oceanographic consulting service if the construction is by a private concern. In the latter case, such a service will cost about $\$ 5,000$ to $\$ 10,000$ per year. While this amount may sound like a large figure for a type of service not commonly employed in the construction industry, the Gulf coast oil operators are finding such a service saves far more than it costs, particularly in reducing loss and damage to marine equipment. As a result of this, it is interesting to note that in 1947 , the services of an oceanographic forecasting firm were used in drilling fewer than $25 \%$ of the wells in the Gulf of Mexico. This percentage has risen to over $85 \%$ today. In no case has an operator falled to renew his contract for the service when the information was being supplied by a well-qualified consulting organization.

\section{SUMMARY}

To summarize, the costs of marine construction are high and are generally affected by the amount of wave action to which the site is exposed. In the preliminary stages of planning and bidding on such construction projects, the mass of visually and instrumentally observed wave data which already exists can be exploited at nominal cost for guidance in final design and the planning of actual construction by utilizing the work feasibility concept. If wave action proves to be an important consideration, a detailed study of the wave factor based on modern oceanographic knowledge should be made. If wave action makes the actual construction difficult or dangerous, special wave forecasts prepared by competent agencies should be acquired for use in day-to-day operations. As in other technical fields of endeavor, the organization which takes these steps and thereby utilizes the best scientific information bearing on an operating problem will ultimately enjoy better resulta in the long run than a concern which does not.

\section{ACKNOWLEDGMENT}

The authors wish to thank A. H. Glenn of A. H. Glenn and Associates, New Orleans, Louisiana for permission to use Table I concerning work feasibility.

\section{REFERENCES}

Bates, C.C. (1948). Utilization of tabulated sea and swell data: Presented at the Twenty Ninth Annual Meeting of the Amer. Geophys. Union, Washington, D.C.

Glenn, A.H. (1950). Progress report on solution of wave, tide, current, and hurricane problems in coastal operations: 011 and Gas Journal, vol. 49, pp. $174-177$.

Hydrographic office, U.S. Navy (1943-1950). Atlas of sea and swell charts: Misc. Publ. No. 10,712, A through D, (published at intervals between 1943 and 1950).

Shepard, F.P., and LaFond, E.C. (1940). Sand movements along the Scripps Institution pier: Amer. Jour. of Science, vol. 238, pp. 272-285. 